\title{
Quando as Notícias mais Compartilhadas são Falsas: a Circulação de Boatos durante a Semana do Impeachment no Facebook
}

\author{
When the most Shared news is False: the Rumor Circulating during the \\ Impeachment Week on Facebook

\section{Cuando las Noticias más compartidas son Falsas: la Circulación de Boatos durante la Semana del Impeachment en Facebook}

\author{
Ada C. Machado da Silveira ${ }^{1}$ \\ Carlos Sanchotene ${ }^{2}$ \\ Suélen de Lima Lavarda ${ }^{3}$
}

\section{Resumo}

$\mathrm{Na}$ semana que antecedeu a votação da abertura do processo de Impeachment da Presidente Dilma Rousseff, três das cinco notícias mais compartilhadas no Facebook eram falsas. Este trabalho busca analisar a circulação das três notícias e sua propagação a partir dos comentários de leitores por meio de uma observação assistemática. Em um primeiro momento abordamos as características dos boatos para, em seguida, discutir as redes sociais digitais e a circulação de boatos. A partir dos comentários foram identificadas três categorias de leitores: questionadores, apoiadores e alertas. Entre os resultados, apontamos que as especificidades do ambiente digital potencializam a propagação de informações falsas, sobretudo pela velocidade de difusão dos conteúdos e pelo potencial de alcance a inúmeros indivíduos.

\begin{tabular}{|c|c|}
\hline \multirow{3}{*}{ 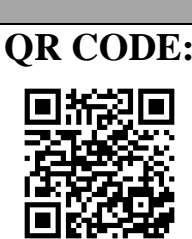 } & Acesse este artigo online \\
\hline & $\begin{array}{l}\text { Website: } \\
\text { http://www.revistas.ufg.br/index.php/ci }\end{array}$ \\
\hline & $\begin{array}{l}\text { DOI: } \\
\text { http://dx.doi.org/10.5216/ci.v20i3.46950 }\end{array}$ \\
\hline
\end{tabular}

Palavras-chave: Circulação de notícias. Boatos. Impeachment. Facebook.

\section{Abstract}

In the week leading up to the vote on the opening of President Dilma Rousseff's Impeachment process, three of the five most shared news on Facebook were fake. This paper aims to analyze the circulation of the three news stories and their propagation from readers' comments through unsystematic observation. At first we discussed the characteristics of the rumors to then discuss digital social networks and the circulation of rumors. From the comments were identified three categories of readers: questioners, supporters and alerts. Among the results, we pointed out that the specificities of the digital environment enhance the propagation of false information, mainly due to the speed of diffusion of the contents and the potential of reach to numerous individuals.

Keywords: News circulation. Rumors. Impeachment. Facebook.

\section{Resumen}

\footnotetext{
${ }^{1}$ Professora do PPG Comunicação da Universidade Federal de Santa Maria (UFSM) e pesquisadora do CNPq, líder do Grupo de Pesquisa Comunicação, Identidades e Fronteiras. E-mail: ada.silveira@ufsm.br.

${ }^{2}$ Pós-doutor em Comunicação na Universidade Federal de Santa Maria (UFSM). Doutor em Comunicação e Cultura Contemporâneas pela Universidade Federal da Bahia (UFBA). E-mail: carlos_sanchotene@yahoo.com.br ${ }^{3}$ Acadêmica do $5^{\circ}$ semestre de Jornalismo na Universidade Federal de Santa Maria (UFSM), bolsista Pibic-AAf/CNPq. E-mail: suelenlavarda@hotmail.com
}

Comun. \& Inf., Goiânia, GO, v. 20, n. 3, p. 99-112, out./dez. 2017 
En la semana que precedió a la votación de la apertura del proceso de Impeachment de la Presidenta Rousseff, tres de las cinco noticias más compartidas en Facebook eran falsas. Este trabajo busca analizar la circulación de las tres noticias y su propagación a partir de los comentarios de lectores por medio de la observación asistemática. En un primer momento abordamos las características de los rumores para luego discutir las redes sociales digitales y la circulación de rumores. A partir de los comentarios se identificaron tres categorías de lectores: cuestionadores, partidarios y alertas. Entre los resultados, señalamos que las especificidades del ambiente digital potencian la propagación de informaciones falsas, sobre todo por la velocidad de difusión de los contenidos y por el potencial de alcance a innumerables individuos.

Palabras clave: Circulación de noticias. Boatos. Impeachment. Facebook.

\section{INTRODUÇÃO}

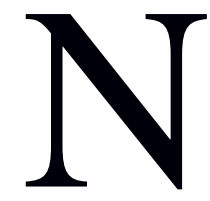

a semana que antecedeu a votação da abertura do processo de Impeachment de Dilma Rousseff, três das cinco notícias mais compartilhadas no Facebook eram falsas. As informações foram divulgadas pelo Grupo de Pesquisa em Políticas Públicas de Acesso à Informação da USP que investigou o desempenho de 8.290 reportagens, publicadas por 117 jornais, revistas, sites e blogs noticiosos ao longo daquela semana de 12 a 16 de abril de 2016 (GPOPAI, 2016).

Os três boatos convertidos em notícias foram os seguintes:

- "Polícia Federal quer saber os motivos para Dilma doar R \$ 30 bilhões a Friboi", do site Pensa Brasil ( $3^{\circ}$ lugar no ranking geral da semana, com 90.150 compartilhamentos);

- "Presidente regional do PDT ordena que militância pró-Dilma vá armada no domingo: 'Atirar para matar'", do site Diário do Brasil (4º lugar, com 65.737 compartilhamentos);

- "Lula deixa Brasília às pressas ao saber de nova fase da Lava-Jato. Seria um mandado de prisão?", do site Diário do Brasil (5 lugar, com 58.601 compartilhamentos).

O conjunto chama atenção pela constatação de que as notícias são todas de cunho político, ligadas ao governo Dilma e ao ex-presidente Lula. A semana representou um momento emblemático para a história do Brasil e a proliferação de rumores acabou sendo potencializada nas redes sociais digitais, pois é um tipo de informação que circula na rede com a intenção de ser tomada como verdadeira (REULE, 2008). As especificidades do ambiente online potencializam a propagação de informações falsas, sobretudo pela velocidade de difusão dos conteúdos e pelo alcance de indivíduos que, por sua vez, se apropriam desses conteúdos, compartilhando e recirculando os rumores no ambiente virtual (ZAGO, 2010).

Nesse sentido, o presente artigo busca analisar a circulação virtual das três notícias falsas mais compartilhadas ao longo da semana do Impeachment e sua propagação a partir dos comentários dos leitores. Em um primeiro momento discutimos as características dos boatos

Comun. \& Inf., Goiânia, GO, v. 20, n. 3, p. 99-112, out./dez. 2017 


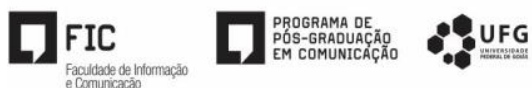

(RENARD, 2007; ROUQUETTE, 1990), em seguida abordamos a circulação e o jornalismo em redes sociais digitais (RECUERO, 2009). Após, são apresentados os procedimentos metodológicos empregados, seguidos da exposição dos resultados e sua discussão. Ao final são traçadas algumas considerações, apontando que as especificidades do ambiente digital potencializam a propagação de informações falsas, sobretudo pela velocidade de difusão dos conteúdos e pelo alcance potencial de inúmeros indivíduos.

\section{SOBRE RUMORES E BOATOS}

De acordo com Renard (2007), o fenômeno do boato é tão antigo quanto a palavra humana. Ele permanece, ainda hoje, como uma de nossas fontes de informação, apesar da existência dos grandes meios de difusão coletiva que são a imprensa, o rádio, a televisão e, atualmente, a internet. Para o autor, o boato deve ser distinguido de duas maneiras: Boato como informação não verificada e Boato como informação falsa.

No primeiro caso, não se prejulga a veracidade do "barulho" que ocorre, logo, o boato não é, necessariamente, falso. De acordo com Renard (2007) alguns "boatos" se revelam exatos: a doença ou a filha desconhecida de um Presidente da República francesa, por exemplo. Nesse caso, não se trata mais de "boato", mas, simplesmente, de "informação, um saber sobre a realidade". No segundo caso, a presença de um boato acontece se determinada informação é verificada e inexata. Trata-se de uma "falsa novidade", na qual as pessoas acreditaram ou ainda acreditam

Para Michael-Louis Rouquette (1990), o boato possui quatro características diferentes:

a) A instabilidade - ocorre quando o conteúdo da mensagem muda. $\mathrm{O}$ boato se forma e, simetricamente, depois de um período de relativa estabilidade, ele se adapta a novos lugares (por exemplo, ao passar de um grupo de amigos para outro ou de uma cidade para outra);

b) A implicação - ocorre quando o boato interessa aos indivíduos e estes passam a retransmitir a informação.

c) A negatividade - trata-se de um acontecimento considerado infeliz ou detestável ou alerta para um perigo. Podemos adiantar três explicações dessa negatividade dos boatos: 1. As más notícias são consideradas mais "vitais" do que as boas, sobretudo, em se tratando de alertas: elas nos permitem tomar certas medidas e precauções; 2. A desvalorização das pessoas ou dos objetos evidenciados pelos boatos negativos tem por 
corolário a valorização de outras pessoas e de outros objetos. Concretamente, falar mal do outro é, indiretamente, falar bem de si e da pessoa para a qual se retransmite o boato. 3. O sucesso dos boatos negativos é próximo dos faits divers trágicos - "nós ficamos fascinados, ou seja, simultaneamente interessados e horrorizados pela desordem, pelo mórbido e pelas transgressões do que é proibido" (RENARD, 2007, p. 98).

d) A última característica do boato é a atribuição ocorrida quando aquele que recebe o boato acredita no que foi recebido, pois atribui confiança à fonte (ROUQUETTE, 1990). Para Reule (2008), boato e rumor são sinônimos e suas definições remetem-se mutuamente. Ambas se referem à forma como determinada informação é espalhada e não ao seu conteúdo. Assim, a veracidade não seria, a princípio, algo que se pudesse questionar quando se fala em boatos ou rumores: "No entanto, é exatamente a forma como é passada a informação (anonimamente, sussurrada ou gritada) que levanta a dúvida sobre sua autenticidade" (REULE, 2008, p. 19). A autora ressalta que o processo de transmissão do boato é uma forma de comunicação e define boato com um tipo de informação não confirmada que se propaga em rede e que circula com o objetivo de ser verdadeira. Sendo informação, é parte de um processo de comunicação que, por sua vez, é um fenômeno social por si mesmo.

Já Sunstein (2010) acredita que é impossível dar uma definição específica para boatos. $\mathrm{O}$ autor prefere usar o termo para fazer referência a alegações de fatos que ainda não foram comprovados, "embora passem de uma pessoa para outra e, portanto, tenham credibilidade não porque se conheçam evidências diretas para corroborá-los, mas porque parece que outras pessoas acreditam neles" (SUNSTEIN, 2010, p. 7). De acordo com ele, os propagadores de boatos podem ser estritamente egoístas (se favorecem prejudicando alguém), egoístas (atraem leitores ou internautas através de boatos), altruístas (quando estão ligados a alguma espécie de causa) e maldosos (que espalham com o intuito de prejudicar os outros, sem favorecimento a si ou a uma causa).

\section{REDES SOCIAIS DIGITAIS E CIRCULAÇÃO DO BOATO}

Compreendemos que as redes sociais modificaram a esfera global das notícias e as práticas jornalísticas, envolvendo um número maior de produtores e distribuidores de notícias, dado que uma importante parcela deles não faz parte de organizações jornalísticas (HEINRICH, 2011). Com as possibilidades do fazer jornalístico na contemporaneidade, a conversação 
tornou-se potencializada e engendrada por uma dinâmica que envolve atores sociais (empresas jornalísticas e leitores) atuando de forma descentralizada, colaborativa e participativa.

Recuero (2009) discute algumas intersecções dos processos de difusão de informações nas redes sociais online e as práticas do jornalismo a partir de três relações: a) redes sociais como fontes produtoras de informação; b) redes sociais como filtros de informações e c) redes sociais como espaços de reverberação dessas informações. Sobre o primeiro aspecto, sabemos que nas redes sociais online é possível encontrar especialistas que auxiliam na construção de pautas, assim como informações em primeira mão. Os pontos negativos, conforme a autora, seriam a avalanche de informações e a falta de credibilidade. Nesse sentido, qualquer indivíduo pode ser uma potencial fonte para o jornalismo, cabendo ao profissional estabelecer critérios que avaliem a credibilidade das fontes.

As redes sociais online também atuam como filtragem de informações, de forma a coletar e republicar as informações obtidas através de veículos informativos ou mesmo de forma a coletar e a republicar informações observadas dentro da própria rede. Estes são os casos mais comumente observados em termos de difusão de informações (RECUERO, 2009). É o caso, por exemplo, dos "retweets" no Twitter e do "compartilhar" no Facebook, por exemplo. Ambos os procedimentos acontecem quando alguém republica no sistema uma informação originalmente publicada por outra pessoa/perfil/organização jornalística.

Jenkins, Ford \& Green (2013) chamam atenção para o fato de que as pessoas não estão compartilhando apenas por conta das possibilidades oferecidas pelas novas tecnologias, mas sim porque já faziam pessoalmente:

Enquanto as novas ferramentas têm proliferado a maneira pela qual as pessoas podem difundir materiais, fazer recomendações boca a boca e partilhar conteúdos midiáticos é um impulso que há muito tempo conduz a forma como as pessoas interagem umas com as outras. Talvez nada seja mais humano do que compartilhar histórias [...] $]^{4}$ (JENKINS; FORD; GREEN, 2013, p. 2-3, tradução nossa).

Assim, as redes sociais online constituem-se em novos espaços de circulação, recirculação e discussão de informações, onde as notícias, por exemplo, são reverberadas (RECUERO, 2009). No entanto, quando se fala em boato, nem todo público que recebe uma

\footnotetext{
${ }^{4}$ Texto original: "While new tools have proliferated the means by which people can circulate material, word-ofmouth recommendations and the sharing of media content are impulses that have long driven how people interact with each other. Perhaps nothing is more human than sharing stories, whether by fire or by "cloud" (JENKINS; FORD; GREEN, 2013, p. 0203).
}

Comun. \& Inf., Goiânia, GO, v. 20, n. 3, p. 99-112, out./dez. 2017 
notícia proveniente do ambiente virtual possui condições de reconhecer se o fato possui veracidade ou não.

Ao receber o rumor, o indivíduo permanece num estado de dúvida sobre o significado dos eventos ocorridos ou mesmo sobre quais eventos ainda podem ocorrer. Na ausência de notícias formais, ele busca mais informações em suas redes sociais, ampliando a propagação do rumor. (REULE, 2008, p. 24).

Quando o receptor acredita no boato, ele compartilha o conteúdo fazendo recircular em sua rede de contatos. Para Reule (2008), há duas condições essenciais para que um boato seja assimilado e, em seguida, se espalhe. A primeira é a ambiguidade, no sentido de obscuridade: "Ambíguo é tudo aquilo que tem (ou pode ter) diferentes sentidos, permitindo interpretações diversas ou mesmo contrárias" (REULE, 2008, p. 24). A outra condição é a importância que um acontecimento ou uma situação tem para elas: "A relevância do conteúdo de uma mensagem vai variar de acordo com o meio social em que esta circula e as emoções envolvidas no processo" (REULE, 2008, p. 25).

Diversas estratégias podem ser utilizadas para dar credibilidade a um boato difundido virtualmente, de modo a persuadir o receptor a tomá-lo por verdade e a repassá-lo, como: usar expressões apelativas ou ao associar o fato a nomes ou instituições respeitadas (REULE, 2008). O público acaba acreditando que a notícia é verdadeira mesmo que ela não possua fontes confiáveis ou apuração adequada. A confirmação ou não confirmação de um boato pode virar notícia (ZAGO, 2010).

Para Iasbeck (2000), boatos e rumores são clamores que chamam a atenção de um número relativamente grande de pessoas e incomodam o fluxo rotineiro da comunicação ao atropelarem relações previsíveis que desalojam expectativas, instaurando inseguranças. Com a internet e as redes sociais, acelera-se em muito o tempo de propagação de um boato. Pode haver um ganho de eficiência na disseminação da economia de tempo, e também considerável perda de qualidade quando verificamos a ausência do contato físico e da proximidade que a transmissão oral proporciona. Logo, compromete a credibilidade e, por consequência, frustra a continuidade da divulgação do boato.

\section{PROCEDIMENTOS METODOLÓGICOS}

Na busca por compreender como se deu a circulação do boato e sua propagação a partir dos comentários dos leitores, realizamos uma observação assistemática sobre as três notícias falsas compartilhadas no Facebook durante a semana de 12 a 16 de abril de 2016. Trata-se da

Comun. \& Inf., Goiânia, GO, v. 20, n. 3, p. 99-112, out./dez. 2017 
semana que antecedeu a votação da abertura do processo de Impeachment da Presidente Dilma Rousseff.

Após a divulgação das notícias pelo Grupo de Pesquisa em Políticas Públicas de Acesso à Informação da USP, visitamos as fanpages dos sites que originaram o boato (PENSA BRASIL, 2016; DIÁRIO DO BRASIL, 2016). No quadro 1 apresentamos uma sistematização das matérias selecionadas para a análise. É importante destacar que o levantamento da USP foi realizado por meio de ferramentas digitais que mapeiam, de hora em hora, todas as reportagens publicadas por diferentes veículos de comunicação selecionados e verifica seus compartilhamentos a partir de um sistema oferecido pelo próprio Facebook. Logo o número de compartilhamentos difere do encontrado diretamente nas fanpages de Pensa Brasil e Diário do Brasil:

Quadro 1 - Detalhamento do corpus de análise

\begin{tabular}{|l|c|c|c|c|}
\hline \multicolumn{1}{|c|}{ Notícia } & Veículo & $\begin{array}{c}\mathrm{N}^{\circ} \text { de } \\
\text { comentários }\end{array}$ & Período & $\begin{array}{c}\mathrm{N}^{\circ} \text { de } \\
\text { compartilhamentos }\end{array}$ \\
\hline $\begin{array}{l}\text { "Lula deixa Brasília às pressas ao } \\
\text { saber de nova fase da Lava-Jato. Seria } \\
\text { um mandado de prisão?" }\end{array}$ & $\begin{array}{c}\text { Diário do } \\
\text { Brasil }\end{array}$ & 468 & $\begin{array}{c}10 / 03 / 2016 \text { à } \\
13 / 04 / 2016\end{array}$ & 7.483 \\
\hline $\begin{array}{l}\text { "Presidente regional do PDT ordena } \\
\text { que militância pró-Dilma vá armada } \\
\text { no domingo: 'Atirar para matar" }\end{array}$ & $\begin{array}{c}\text { Diário do } \\
\text { Brasil }\end{array}$ & 1.031 & $\begin{array}{c}13 / 04 / 2016 \text { e } \\
14 / 04 / 2016\end{array}$ & 17.734 \\
\hline $\begin{array}{l}\text { "Polícia Federal quer saber os motivos } \\
\text { para Dilma doar R\$ 30 Bilhões a } \\
\text { Friboi" }\end{array}$ & Pensa Brasil & 18.548 & $\begin{array}{c}12 / 04 / 2016 \text { à } \\
08 / 06 / 2016\end{array}$ & 34.708 \\
\hline
\end{tabular}

Fonte: elaboração dos autores a partir de dados divulgados pelo Grupo de Pesquisa em Políticas Públicas de Acesso à Informação da USP

\section{RESULTADOS E DISCUSSÃO}

A matéria da figura 1 foi a quinta história mais compartilhada; ela sugere que Lula teria deixado Brasília após saber de nova fase da Lava-Jato. A notícia foi compartilhada, pela primeira vez, no dia 10 de março, às vésperas da Operação-Xepa, na qual não houve nenhuma menção ao ex-Presidente. Ao analisarmos a matéria, o que mais chama atenção é a forma de tratamento que o veículo dá para a suposta pessoa intimada, o ex-presidente Lula, utilizando expressões como abatido, preocupado e risco.

O título "Lula deixa Brasília às pressas ao saber de nova fase da Lava-Jato. Seria um mandado de prisão?" praticamente condena Lula à prisão. O questionamento no título induz que o leitor forme o pensamento no sentido de condenar Lula sem mesmo ler a primeira linha da notícia. Não há uma contextualização sobre a possibilidade do ex-Presidente ser preso, apenas comentários sobre os riscos sem fontes jornalísticas seguras. O boato atingiu a marca de 7.483 compartilhamentos.

Comun. \& Inf., Goiânia, GO, v. 20, n. 3, p. 99-112, out./dez. 2017 


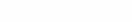

Figura 1 - "Lula deixa Brasília às pressas ao saber de nova fase da Lava-Jato. Seria um mandado de prisão?"

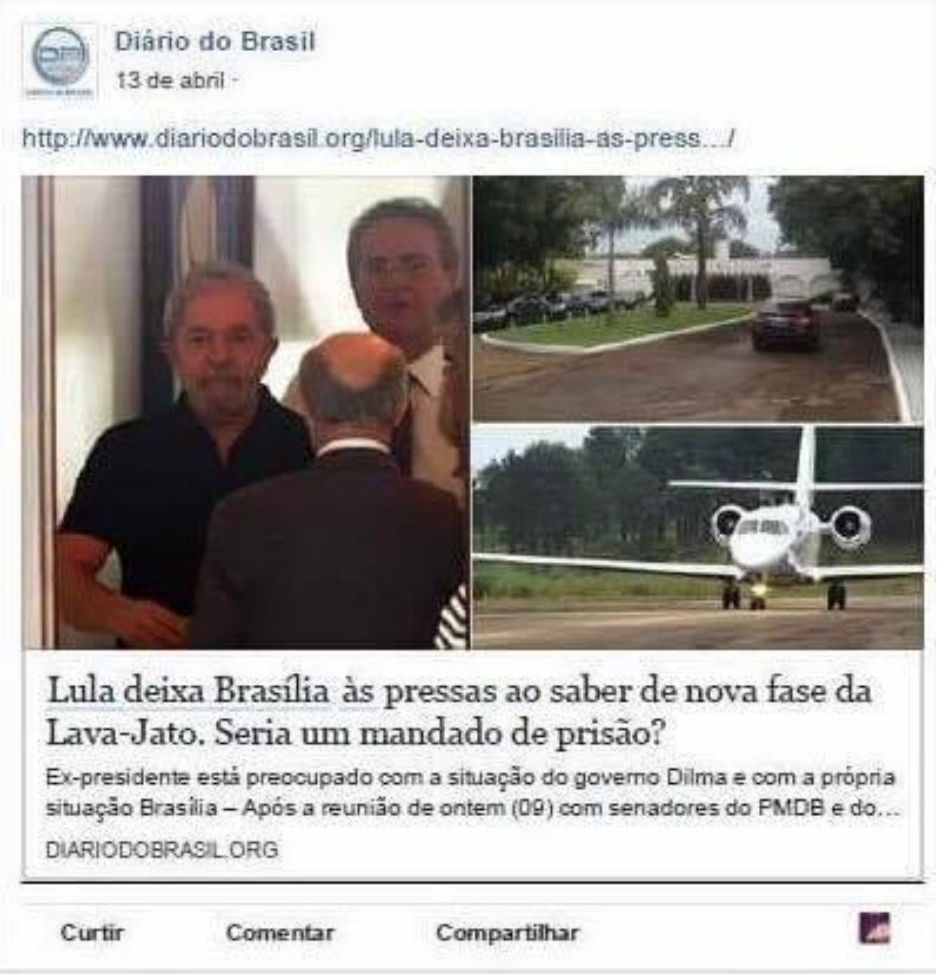

Fonte: Facebook Diário do Brasil. Capturado em: 15/06/2016

O terceiro lugar do ranking geral da semana obteve 34.708 mil compartilhamentos e refere-se à notícia de que a Presidente Dilma teria concedido anistia à dívida de $\mathrm{R} \$ 30$ bilhões da empresa de carnes Friboi com o BNDES. A linguagem da matéria é de modo geral coloquial. Logo na "linha fina" pode-se notar o uso de palavras como "povão" e "cartel de carnes". Na matéria, o termo "povão" se refere à população brasileira de classe baixa, que paga impostos. Segundo o veículo, "juros que nem sonham que existam", levam o leitor a entender que esta classe não tem conhecimento sobre o que acontece na economia do país.

"Agora vem a anistia. Em outras palavras, Dilma disse a Friboi: 'A crise chegou em vocês, então, não precisam pagar o empréstimo, coitadinhos' (Deboche da Redação)". Por meio do enunciado o veículo utiliza uma suposta fala da Presidente Dilma de modo interpretativo. Fica claro que o site coloca total opinião no acontecimento, deixando de lado a objetividade. $\mathrm{O}$ boato foi desmentido pelo controlador do frigorífico.

Figura 2 - "Polícia Federal quer saber os motivos para Dilma doar R\$ 30 bilhões a Friboi" 


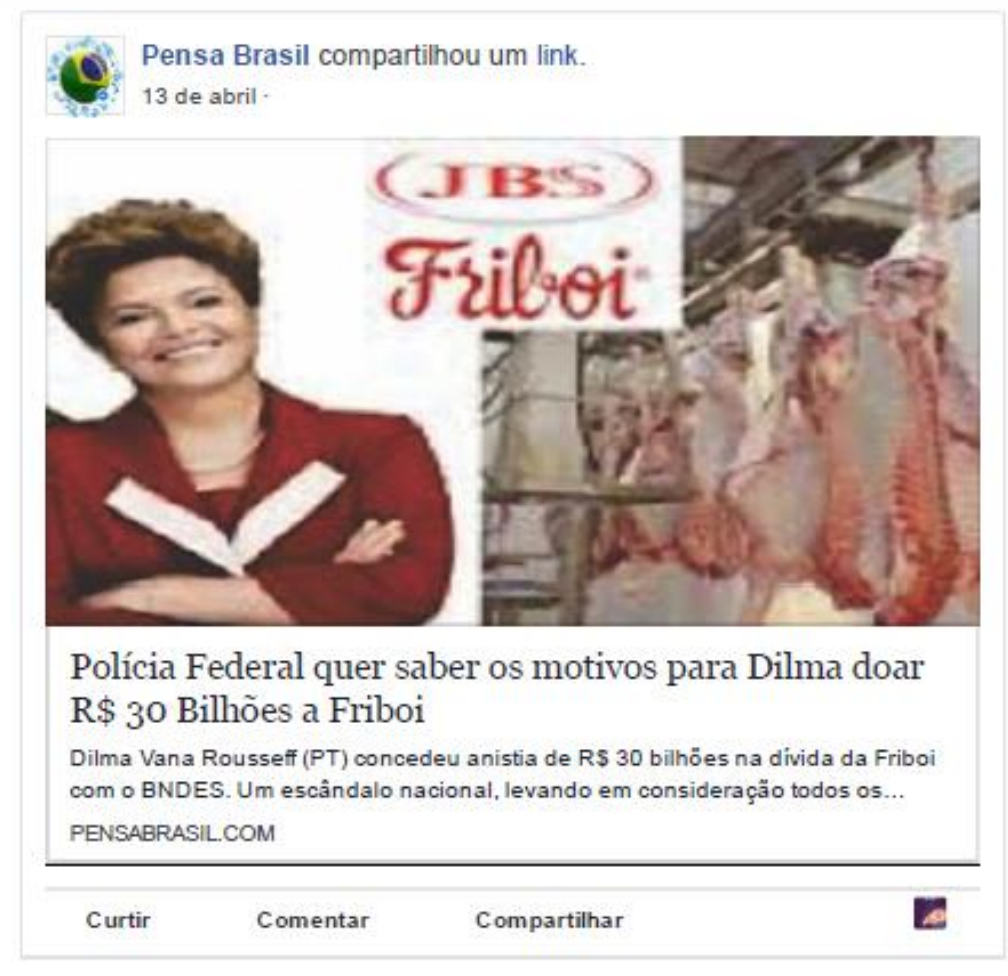

Fonte: Faceboook Pensa Brasil. Capturado em: 15 jun. 2016

A terceira notícia informa que José Silvio dos Santos, suposto Presidente do PDT no Distrito Federal, teria convocado militantes em sua página pessoal no Facebook para "atirarem" em parlamentares: "Quero todo mundo armado". O falso Presidente ainda teria solicitado aos seus leitores que levassem cordas, invadissem a Câmera e o Senado, além de enforcar os deputados e senadores golpistas. Na matéria, o veículo afirma que teve acesso a uma entrevista feita pelo site Antagonista com José Silvio, onde o mesmo confirmou a publicação da convocação em seu perfil. Porém, a falsa informação está no cargo que o site dá ao cidadão.

O principal desmentido ao boato vem do PDT, em nota oficial assinada por seu presidente no Distrito Federal, Georges Michel Sobrinho: "O PDT torna público que este cidadão, por não ter nenhuma autorização para se manifestar em nome da instituição, foi expulso do quadro de filiados do partido", diz a nota. Mesmo que a notícia tenha sido desmentida, o site Diário do Brasil insiste na veracidade da notícia.

Figura 3 - "Presidente regional do PDT ordena que militância pró-Dilma vá armada no domingo: 'Atirar para matar'" 


\section{Diário do Brasil}

14 de abril.

http://www.diariodobrasil.org/presidente-do-pdt-ordena-que...l

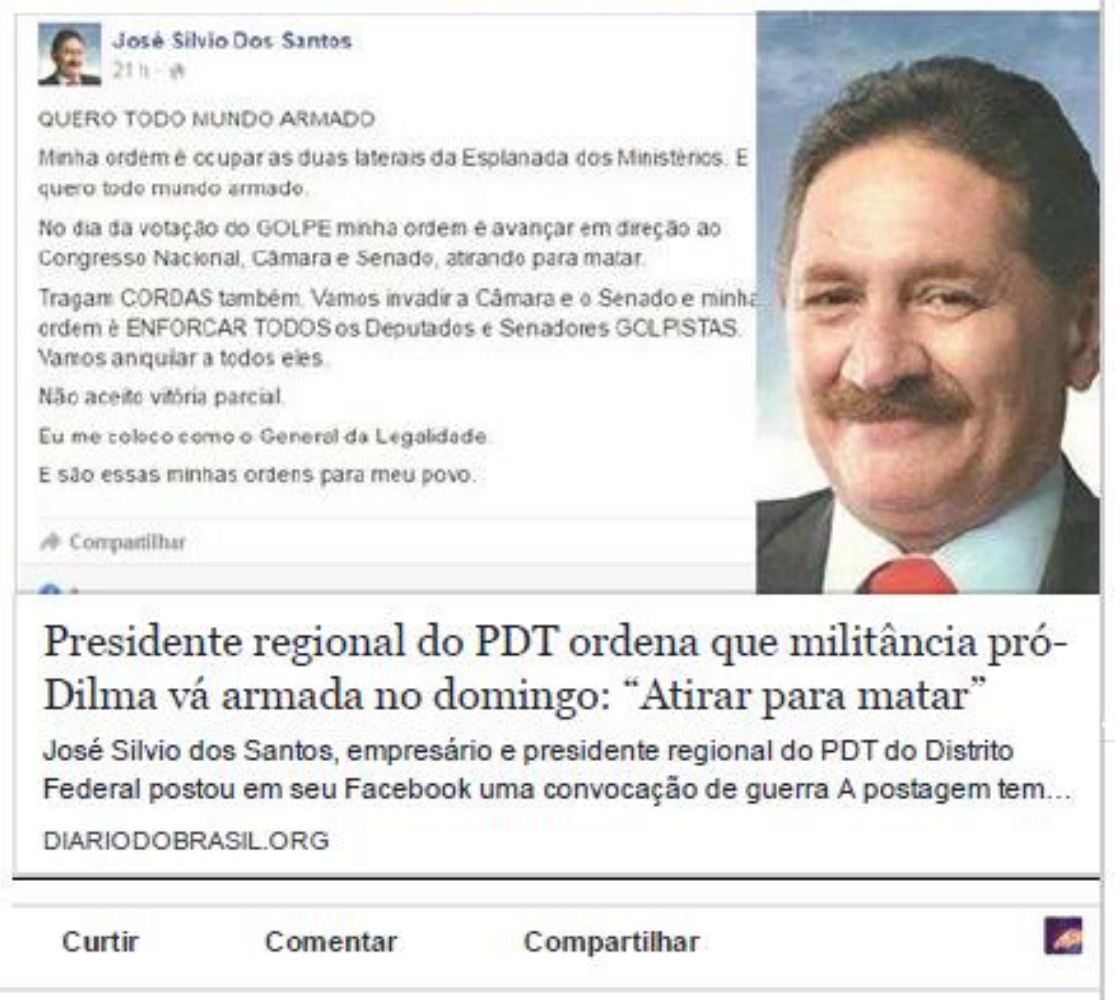

Fonte: Facebook Diário do Brasil. Capturado em: 15/06/2016

Nas matérias falsas analisadas encontramos algumas características do boato (ROUQUETTE, 1990). A “implicação” torna-se presente nas três notícias. Ou seja, elas são publicadas ao longo de uma semana crucial para a política brasileira envolvendo atores sociais ligados ao processo do Impeachment. Já a "negatividade" é visível no momento que os veículos se referem de modo pejorativo aos atores sociais protagonistas dos boatos: Lula, Dilma e José Silvio. E a "atribuição" ocorre no momento que os sites divulgam a notícia e o público a toma como verdadeira.

Outro dado diz respeito sobre as republicações. A mesma notícia falsa acabou sendo postada diversas vezes ao longo dos meses de abril, maio e junho. A matéria "Polícia Federal quer saber os motivos para Dilma doar R \$ 30 bilhões a Friboi” foi postada na fanpage de Pensa Brasil vinte e uma vezes. "Presidente regional do PDT ordena que militância pró-Dilma vá armada no domingo: 'Atirar para matar'" foi postada duas vezes na fanpage de Diário do Brasil. Já "Lula deixa Brasília às pressas ao saber de nova fase da Lava-Jato. Seria um mandado de prisão?" foi postada três vezes. 


\section{PROPAGAÇÃO A PARTIR DOS COMENTÁRIOS}

Os leitores, além de ajudar na propagação do boato por meio de compartilhamentos, também deixam opiniões, questionamentos, apoio, reclamações e diálogos nos comentários de cada postagem. A partir da observação assistemática dos comentários nas publicações, podemos classificá-los em três categorias: questionadores, apoiadores e de alerta.

\subsection{QUESTIONADORES}

O público não possui certeza da veracidade da notícia. No momento de dúvida, o leitor acaba procurando novas informações sobre o fato e ajuda a circular ainda mais o rumor (REULE, 2008). De modo geral é impossível, na vida cotidiana, checar todas as informações que recebemos (RENARD, 2007). Sendo assim, o leitor acredita e compartilha o boato, conforme os comentários abaixo destacados:

Alceu Egilio Michelon Continuo em dúvida. Como os políticos e o Lula se locomovem com tanta rapidez e em questão de horas trocam de cidade e estado como se fossem o "Super Homem". Vou ficar com meus gibis de antigamente. Não quero ser paciente de psicólogos.

Curtir - Responder - $\quad 1 \cdot 10$ de março às 13:38

Fonte: facebook.com/DiariodoBrasil

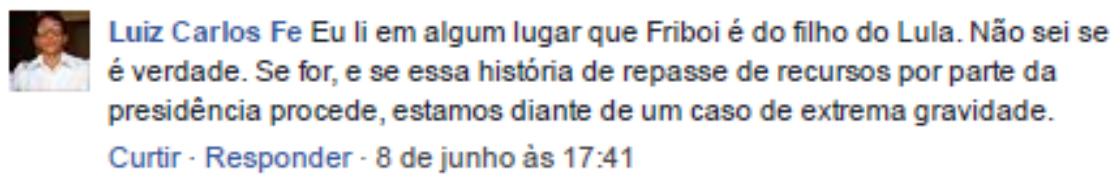

Fonte: facebook.com/PensaBrasil

\subsection{APOIADORES}

Pela falta de informações, fontes seguras e identidade com o veículo, o leitor atribui valor positivo à notícia, dá credibilidade ao veículo e ajuda na circulação da mesma. Em alguns casos, pode-se notar um discurso de ódio aos atores sociais citados na notícia. Juntando a falta de informação do leitor e a mecânica das redes sociais, a notícia acaba se espalhando (JENKINS; FORD; GREEN, 2013) rapidamente.

A quarta característica dos boatos, segundo Rouquette (1990), é a atribuição. Trata-se da fonte designada pelo narrador como garantia de veracidade da informação. Esta característica foi encontrada através de alguns comentários. No momento que o leitor se informa por meio de um determinado veículo que julga confiável, ele acaba compartilhando por acreditar e confiar na fonte. Ao mesmo tempo, há o leitor apoiador e o de alerta. No momento 
que o apoiador ajuda na circulação do boato, o de alerta serve de auxílio, questionando a veracidade da fonte, conforme os comentários abaixo:

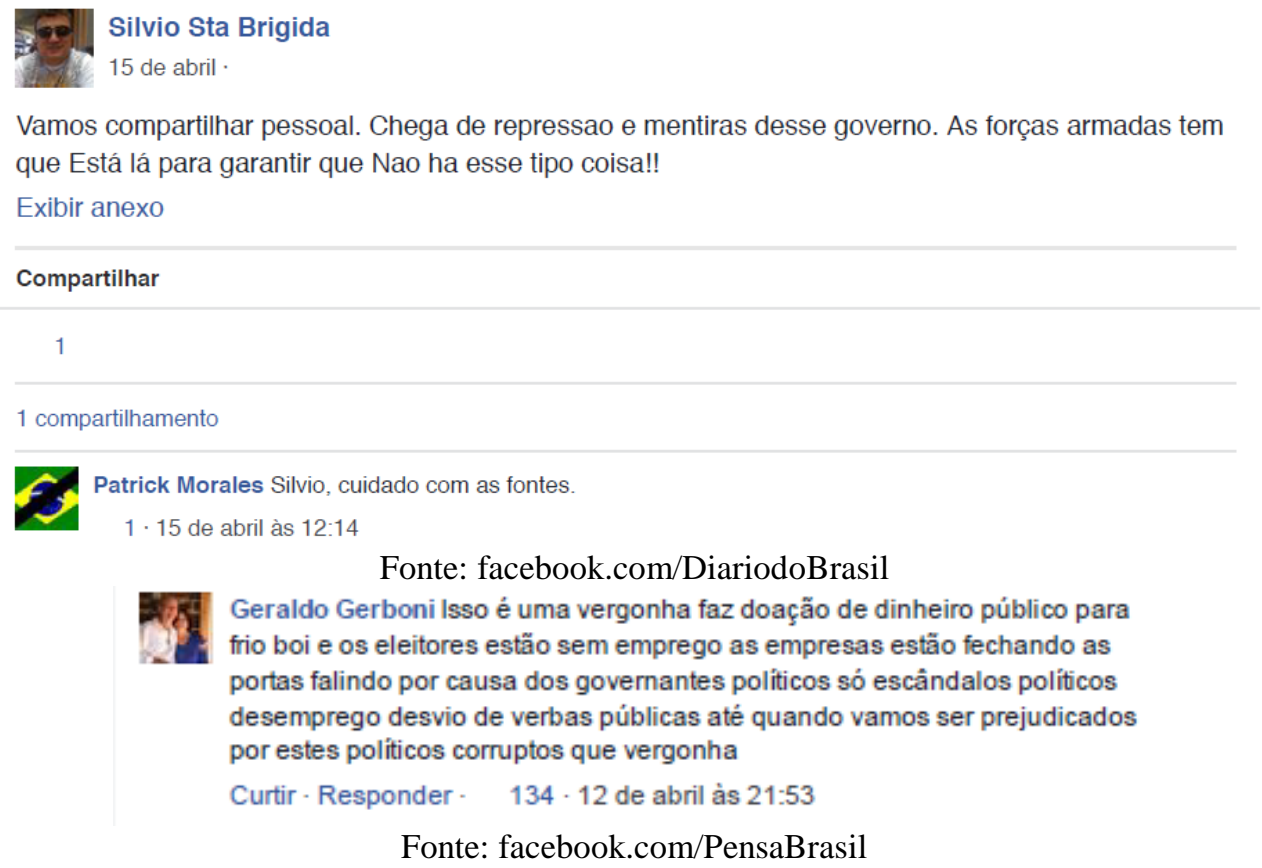

\subsection{DE ALERTA}

Se de um lado a internet oferece meios para que os boatos se espalhem rapidamente, ela também pode auxiliar no processo de checagem da informação. Tendo a certeza de que a notícia não é verídica, o leitor acaba servindo de alerta a outros leitores do boato. E, em alguns casos, critica e desmente o que foi compartilhado, conforme os exemplos a seguir:

Patricia Pardo ja vi essa foto antes, uffffff quanta manipulação de informação

Curtir - Responder - 10 de março às 14:22

Fonte: facebook.com/DiariodoBrasil

Gustavo Born Voces estão colocando reportagens antigas .... o Brasil já esta um caos, desnecessário colocar reportagens antigas para causar mais stress. Tenho certeza que esse não é o intuito dessa página. $O$ Oráculos deve ser para as profecias, para a elevação de pensamentos e ondas vibratórias de paz.

Curtir - Responder - $\quad 1 \cdot 29$ de março às 10:31

Fonte: facebook.com/DiariodoBrasil

\section{CONSIDERAÇÕES FINAIS}

Ao observarmos a circulação de boatos, percebemos que eles possuem algumas características em comum: não são datados, são imprecisos, são usados em diversas situações

Comun. \& Inf., Goiânia, GO, v. 20, n. 3, p. 99-112, out./dez. 2017 
e contextos, não apresentam fontes, aparecem e somem diversas vezes na rede e são compostos por conteúdos com forte apelo emocional, tal como indignação e revolta.

Os resultados apresentados servem para refletirmos sobre os modos como os usuários consomem informações nas redes sociais e o tipo de jornalismo que é produzido e compartilhado. Com o uso desenfreado das redes sociais, qualquer pessoa pode publicar o que quiser, mesmo não tendo os conhecimentos necessários. Muitos meios de comunicação estão surgindo e deixando de lado a ética jornalística para ganhar audiência, "curtidas" e seguidores, não se importando com a qualidade e a veracidade dos fatos.

O leitor mais atento e crítico, por um lado, possui condições de verificar e questionar os conteúdos ditos jornalísticos que são publicados na rede, buscando fontes e veículos seguros antes de contribuir com a disseminação da informação. Por outro lado, com o grande número de notícias circulando pela internet, o leitor, majoritariamente, passa a não ter a capacidade de diferenciar se determinado conteúdo é verdadeiro ou não e acaba tomando a maioria dos rumores como verídicos. Assim, ajuda na circulação do boato. Desse modo, precisamos estar atentos às informações que compartilhamos nas redes a fim de que os danos sociais de ampla circulação de boatos sejam minimizados.

Por fim, apontamos que as especificidades do ambiente digital potencializam a propagação de informações falsas, sobretudo pela velocidade de difusão dos conteúdos e pelo alcance de inúmeros indivíduos. O excesso de informação, a popularização de smartphones e a busca por popularidade podem ser um reflexo da vulnerabilidade dos internautas que costumam ler apenas palavras-chave ou o título da notícia. Logo, compartilham a informação facilitando a propagação do boato.

\section{REFERÊNCIAS}

Grupo de pesquisa em políticas públicas de acesso à informação da USP. Disponível em: http://gpopai.usp.br/. Acesso em: 02 jun. 2016.

HEINRICH, A. Network Journalism. Nova Iorque: Routledge, 2011.

IASBECK, L. C. Os boatos: além e aquém da notícia. Lumina, Juiz de Fora, v. 3, n. 2, jul./dez. 2000.

JENKINS, H.; FORD, S.; GREEN, J. Spreadable Media: Creating Value and Meaning in a Networked Culture (Postmillennial Pop). Nova Iorque: NYU Press, 2013.

LULA deixa brasília às pressas ao saber de nova fase da lava-jato: seria um mandado de prisão? 13 abr. 2016. Fanpage Diário do Brasil. Disponível em: 
<https://www.facebook.com/DiariodoBrasil/posts/1191224050942217>. Acesso em: 10 jun. 2016.

POLÍCIA federal quer saber os motivos para Dilma doar R \$ 30 bilhões a Friboi. 13 abr. 2016. Fanpage pensa Brasil. Disponível em:

<https://www.facebook.com/PensaBrasil/posts/1786948538202591>. Acesso em: 20 maio 2016.

PRESIDENTE regional do PDT ordena que militância pró-dilma vá armada no domingo: "atirar para matar". 14 abr. 2016. Fanpage Diário do Brasil. Disponível em: <https://www.facebook.com/DiariodoBrasil/posts/1191902627541026>. Acesso em: 04 jul. 2016.

RECUERO, R. Redes sociais na Internet, difusão de informação e jornalismo: elementos para discussão. In: SOSTER, D.; SILVA, F. F. da. (Org.). Metamorfoses jornalísticas 2: a reconfiguração da forma. Santa Cruz do Sul: EDUNISC, 2009.

RENARD, J. B. Um gênero comunicacional: os boatos e as lendas urbanas. Revista FAMECOS: mídia, cultura e tecnologia, v. 1, n. 32, 2007.

REULE, D. A dinâmica dos rumores na rede: a web como espaço de propagação de boatos virtuais. 2008. 131 f. Dissertação (Mestrado em Comunicação e Informação), Universidade Federal do Rio Grande do Sul, Rio Grande do Sul, 2008.

ROUQUETTE, M.-L. Le syndrome de rumeur. Communications, n. 52, 1990, p. 119-123.

SUNSTEIN, Cass. A verdade sobre os boatos: como se espalham e como acreditamos neles. Rio de Janeiro: ELSEVIER, 2010.

ZAGO, G. da S. "Boatos que Viram Notícia: Considerações sobre a Circulação de informações entre Sites de Redes Sociais e Mídia Online de Referência”. In: CONGRESSO DE CIÊNCIAS DA COMUNICAÇÃO NA REGIÃO SUL, 11., 2010, Novo Hamburgo. Anais eletrônicos... Novo Hamburgo, 2010. Disponível em: http://www.intercom.org.br/papers/regionais/sul2010/resumos/R20-0675-1.pdf. Acesso em: 02 jun. 2016. 